\title{
OS ANTI-SECRETORES ALTERAM A DISTRIBUIÇÃO DO Helicobacter pylori NO ESTÔMAGO
}

\author{
DESCRITORES - Antagonistas dos receptores $\mathrm{H}_{2}$ da histamina. Infecções por helicobacter. \\ Helicobacter pylori. Antro pilórico, microbiologia.
}

Os anti-secretores são medicamentos de primeira linha no tratamento da úlcera péptica (UP) e da doença do refluxo gastroesofagiano (DRGE). Têm sido também utilizados no tratamento de sintomas digestivos altos em pacientes considerados funcionais. Dois grupos de medicamentos são, atualmente, prescritos nas situações citadas: os bloqueadores dos receptores da histamina $\left(\mathrm{BlH}_{2}\right)$ e os inibidores da bomba de prótons (IBP). Estes últimos são considerados como praticamente obrigatórios nos esquemas de tratamento para a erradicação do Helicobacter pylori $(\mathrm{Hp})$, bem como os preferidos para o tratamento tanto da UP como da DRGE.

No Brasil, infelizmente, a prática da auto-medicação e a facilidade da obtenção de medicamentos sem a receita médica constitui a regra. É freqüente o paciente, ao procurar o seu médico, já estar utilizando medicamentos que bloqueiam a produção do ácido clorídrico $(\mathrm{HCl})$. A atual tendência da substituição de medicamentos considerados como habituais no controle de sintomas dispépticos (particularmente os antiácidos) pelos anti-secretores, ampliou ainda mais o uso dos $\mathrm{BlH}_{2}$ e dos IBP.

Que conseqüências eventuais poderia originar este tipo de conduta? O trabalho do Serviço de Gastroenterologia de Juiz de Fora, $\mathrm{MG}^{(2)}$, publicado no presente número dos ARQUIVOS de GASTROENTEROLOGIA, aborda as alterações no diagnóstico da infecção pelo $\mathrm{Hp}$ (teste ultra rápido da urease e exame histológico). Para o teste ultra rápido da urease (Arvind et al., 1988), utilizaram dois fragmentos do antro e dois do corpo e, para o exame anatomopatológico, um fragmento do antro e um do corpo (coloração pelo Giemsa). O uso da ranitidina não resultou em alterações na positividade do teste da urease, nem do exame histológico, tanto no antro, como no corpo. No entanto, naqueles pacientes que receberam o omeprazol, observou-se significativa queda da positividade em antro, tanto para o teste da urease (antes 100\%, após tratamento 64\%), como para o exame histológico (antes 92\%, depois 40\%). No corpo gástrico, o achado foi de certo modo conflitante pois, enquanto no teste da urease a positividade aumentou (de $64 \%$ para 76\%), o exame histológico anteriormente positivo em 21 pacientes $(84 \%)$ após tratamento permitiu demonstrar a presença de bactérias somente em 14 pacientes (56\%).

Ainda que os autores comentem que a redução da positividade foi observada só no antro, não ocorrendo no corpo, a histologia mostrou acentuada redução da positividade do $\mathrm{Hp}$, tanto no antro (antes $92 \%$, depois $40 \%$ ), como no corpo (antes $84 \%$, depois 56\%). As observações de FERREIRA et al. ${ }^{(2)}$ confirmam as da literatura em relação ao comportamento da bactéria no antro frente ao tratamento com IBP, mas conflita com o relatado à migração (ou florescimento) do Hp no corpo ${ }^{(4)}$.

O primeiro grupo a chamar a atenção para o efeito do IBP sobre a colonização das diferentes áreas do estômago pelo Hp foi o de Pádua, Itália. VIGNERI et al. (7), em carta enviada ao Am J Gastroenterol, em 1991, utilizando o omeprazol na dose de $40 \mathrm{mg}$ por 4 a 8 semanas em 29 pacientes com úlcera duodenal refratária, observaram que a presença no antro do Hp que, inicialmente, era de $89,7 \%$, ao final do tratamento passou a ser de 20,7; no terço inferior do corpo passou de $65,5 \%$ para $75,9 \%$ e no terço superior de $44,8 \%$ para $82,8 \%$. Os autores comentam que, em razão da alteração da produção de $\mathrm{HCl}$ pelo uso do IBP, ocorria migração da bactéria do antro para o corpo. Salientam a importância da realização da biopsia no corpo gástrico em pacientes que recebem IBP pois, sendo a pesquisa realizada em fragmentos somente do antro, falsos negativos serão reportados. Na observação deles, a limitação do teste a biopsias do antro resultaria em uma negativação de $69,0 \%$, 
valores comparáveis aos relatados por outros observadores que limitaram a pesquisa da presença da bactéria ao antro, como por exemplo, BIASCO et al. ${ }^{(1)}$.

Outros pesquisadores não só confirmaram as observações de VIGNERI et al. ${ }^{(7)}$, como a correlacionaram com o grau de inflamação(5) e com a evolução para a atrofia da mucosa com o seu uso prolongado ${ }^{(3)}$. MARZIO et al. ${ }^{(6)}$ mostraram que após 4 semanas de omeprazol ocorria significativa diminuição da colonização do antro e o aumento no fundo gástrico; no entanto, somente em pacientes que recebiam o IBP diariamente esta situação persistia. Naqueles randomizados para o uso do omeprazol em dias alternados ou que receberam placebo, ocorria gradativo retorno às condições anteriores e, após 8 meses, a distribuição do Hp voltava a ser igual à observada antes do tratamento. Em $30 \%$ dos pacientes que receberam o omeprazol diariamente por 12 meses, observou-se supressão do Hp, porém 2 meses após a suspensão da medicação, todos os pacientes positivaram. As observações desses autores mostram que na realidade, o omeprazol não tem ação bactericida, mas suprime a capacidade de replicação da bactéria nas regiões de baixa acidez, diminuindo a população bacteriana e/ou induzindo a bactéria a adotar a sua forma cocóide de hibernação. Retornando as condições secretórias do estômago ao seu estado original, maior acidez no corpo e menor no antro, o Hp volta a florescer em seu nicho ecológico preferencial - o antro gástrico.

Qual a importância das observações de FERREIRA et al. ${ }^{(2)} \mathrm{em}$ relação ao que já havia sido sobejamente demonstrado na literatura? As observações do grupo de Juiz de Fora mostram que mesmo um período curto de utilização do IBP (7 dias) é suficiente para suprimir significativamente a presença do Hp no antro. Portanto, impõe-se a pesquisa da bactéria em antro e corpo, mesmo após a administração a curto prazo de potentes anti-secretores. A supressão do Hp no antro pelo omeprazol (teste da urease e exame histológico), confirmou os dados da literatura. No entanto, contrapondo-se ao demonstrado por outros investigadores, no corpo gástrico o exame histológico mostrou diminuição acentuada de casos positivos (de $84 \%$ para $56 \%$ ).

Quais seriam as razões para esta discrepância? Duas possibilidades podem ser aventadas: os testes utilizados para verificar a presença do Hp não foram adequados para aquela situação em particular ou o material para a execução do teste foi qualitativamente ou quantitativamente inadequado. Tudo parece indicar que a utilização de um único fragmento para o exame histológico possa ter sido a razão dos baixos valores de positividade observados no corpo gástrico. Ainda que na rotina seja aceitável (porém não desejável) a utilização de um único fragmento, tanto para o teste da urease, como para o exame histológico, em trabalhos de investigação o mínimo de dois fragmentos de cada região do estômago deve ser preferencialmente obtido.

A distribuição irregular do Hp no estômago e por vezes o pequeno número de bactérias são situações que podem levar a resultados falsos negativos quando o número de biopsias é pequeno. Seria interessante se os autores pudessem realizar em um número adicional de pacientes o exame histológico para constatação do Hp em corpo baixo, médio e alto em um mínimo de dois fragmentos de cada região, estudando possível correlação com a atividade inflamatória nas diferentes áreas do corpo/fundo gástrico. Demonstrando que um período curto de IBP resulta em diminuição significativa da presença do Hp no antro, FERREIRA et al. ${ }^{(2)}$ dão importante contribuição para os que se preocupam com o diagnóstico da infecção pela bactéria, enfatizando que curtos períodos de intensa supressão ácida são suficientes para alterar a sua distribuição no estômago.

Schlioma ZATERKA*

Zaterka S. Antisecretors modify the gastric localization of Helicobacter pylori. Arq Gastroenterol 2001;38(1):1-2.

HEADINGS - Histamine $\mathrm{H}_{2}$ antagonists. Helicobacter infections. Helicobacter pylori. Pyloric antrum, microbiology.

\section{REFERÊNCIAS BIBLIOGRÁFICAS}

1. Biasco G, Miglioli M, Barbara L, Corinaldesi R, di Febo G. Omeprazole, Helicobacter pylori, gastritis, and duodenal ulcer [letter]. Lancet 1989;9:1403.

2. Ferreira LEVV de C, Alterações no teste ultra-rápido da urease e no exame anatomopatológico para Helicobacter Pylori induzidas por drogas antisecretoras. Arq Gastroenterol 2001;38:3-8.

3. Kuipers EJ, Uyterlinde AM, Pena AS, Hazenberg HJ, Bloemena E, Linderman J, Klinkenberg-Knol EC, Meuwissen SG. Increase of Helicobacter pyloriassociated corpus gastritis during acid supressive therapy: implications for longterm safety. Am J Gastroenterol 1995;90:1401-6.
4. Lee A, Mellgard B, Larsson H. Effect of gastric acid on Helicobacter pylori ecology. In: Hunt RH, Tytgat GNJ, editors. Helicobacter pylori. Basic mechanisms to clinical cure. Dordrecht: Academic Publ.; 1996. p.50-63.

5. Logan RP, Walker MM, Misiewicz JJ, Gummett PA, Karim QN, Baron JH. Changes in intragastric distribution of Helicobacter pylori during treatment with omeprazole. Gut 1995;36:12-6.

6. Marzio L, Biasco G, Cifani F, DeFanis C, Falcucci M, Ferrini G, Grossi L, Iannetti G, Larcinese G, Lattanzio R, et al. Short- and long-term omeprazole for the treatment and prevention of duodenal ulcer, and effect on Helicobacter pylori. Am J Gastroenterol 1995;90:2172-6.

7. Vigneri S, Termini R, Scialabba A, Pisciotta G. Omeprazole therapy modifies the gastric localization of Helicobacter pylori. Am J Gastroenterol 1991;86:1276.

* Professor Convidado da Disciplina de Gastroenterologia e do Gastrocentro da Universidade Estadual de Campinas - UNICAMP. Presidente do Núcleo Brasileiro para o Estudo do H. pylori. 